\title{
Mediterranean precipitation climatology, seasonal cycle, and trend as simulated by CMIP5
}

\author{
Colin Kelley, ${ }^{1}$ Mingfang Ting, ${ }^{1}$ Richard Seager, ${ }^{1}$ and Yochanan Kushnir ${ }^{1}$ \\ Received 1 August 2012; revised 5 October 2012; accepted 5 October 2012; published 2 November 2012.
}

[1] Winter and summer Mediterranean precipitation climatology and trends since 1950 as simulated by the newest generation of global climate models, the Coupled Model Intercomparison Project phase 5 (CMIP5), are evaluated with respect to observations and the previous generation of models (CMIP3) used in the Intergovernmental Panel on Climate Change Fourth Assessment Report. Observed precipitation in the Mediterranean region is defined by wet winters and drier summers, and is characterized by substantial spatial and temporal variability. The observed drying trend since 1950 was predominantly due to winter drying, with very little contribution from the summer. However, in the CMIP5 multimodel mean, the precipitation trend since 1950 is evenly divided throughout the seasonal cycle. This may indicate that in observation, multidecadal internal variability, particularly that associated with the North Atlantic Oscillation (NAO), dominates the wintertime trend. An estimate of the observed externally forced trend shows that winter drying dominates in observations but the spatial patterns are grossly similar to the multimodel mean trend. The similarity is particularly robust in the eastern Mediterranean region, indicating a radiatively forced component being stronger there. Results of this study also reveal modest improvement for the CMIP5 multi-model ensemble in representation of the observed six month winter and summer climatology. The results of this study are important for assessment of model predictions of hydroclimate change in the Mediterranean region, often referred to as a "hotspot" of future subtropical drying. Citation: Kelley, C., M. Ting, R. Seager, and Y. Kushnir (2012), Mediterranean precipitation climatology, seasonal cycle, and trend as simulated by CMIP5, Geophys. Res. Lett., 39, L21703, doi:10.1029/2012GL053416.

\section{Introduction}

[2] As a subtropical region, the Mediterranean region is expected to dry as a consequence of rising concentrations of greenhouse gases (GHG) [Intergovernmental Panel on Climate Change (IPCC), 2007]. As a thermodynamic consequence of increasing the atmospheric temperature, wet areas are expected to get wetter and dry areas, such as the subtropics, drier [Held and Soden, 2006; Seager et al., 2007, 2010]. For the current century, the CMIP3 multimodel ensembles predicted a significant drying trend for the Medi-

\footnotetext{
${ }^{1}$ Lamont-Doherty Earth Observatory, Columbia University, Palisades, New York, USA.

Corresponding author: C. Kelley, Lamont-Doherty Earth Observatory, Columbia University, 61 Route 9W, Palisades, NY 10964, USA. (ckelley@1deo.columbia.edu)

(C2012. American Geophysical Union. All Rights Reserved. 0094-8276/12/2012GL053416
}

terranean region [IPCC, 2007]. This "thermodynamic" subtropical drying is coupled with increasing precipitation in higher latitudes and circulation changes, primarily an expanding Hadley Cell and a poleward shift in the midlatitude storm tracks [Yin, 2005; Lu et al., 2007; Wu et al., 2011]. Even in the absence of any future changes in interannual variability, the long-term drying of the Mediterranean will lead to an increase in the likelihood of severe dry years, which would have important consequences for water resource in many Mediterranean countries, especially those already experiencing water insecurity. Whether a precipitation response to increasing radiative forcing has begun to emerge during recent decades, amid the often large natural interannual and multidecadal precipitation variability, is an open question, one that has been the subject of considerable debate [Feldstein, 2002; Schneider et al., 2003; Osborn, 2004; Kelley et al., 2012; Gillett et al., 2003; Thompson et al., 2003].

[3] The previous generation of global climate models (GCMs) from the Coupled Model Intercomparison Project Three (CMIP3) was able to simulate the large-scale climatological features of Mediterranean region precipitation (see Figure 1). In the newest generation of global climate models, the CMIP5, in addition to other model advancements, increased spatial resolution potentially allows improved representation of the climatological pattern and amplitude associated with the complex physiography and orography of the region [Giorgi and Lionello, 2008]. With regard to the trend, the Mediterranean experienced a decline in precipitation since 1950 [Hurrell et al., 2003; Kelley et al., 2012], which could be the result of a combination of low frequency multidecadal variability and response to external forcing via increasing GHG [Osborn, 2004; Kelley et al., 2012; Mariotti and Dell'Aquila, 2012; Hoerling et al., 2012]. The greater Mediterranean drying was not uniform however as there were some southern and eastern subregions that experienced a wetting trend during the second half of the 20th Century [Jacobeit et al., 2007]. This study intends to address how well the CMIP5 models simulate the observed Mediterranean precipitation climatology, seasonal cycle and trends, and to what extent we can trust the multimodel mean (MMM) trends as representing the externally forced trends.

\section{Data and Methods}

\subsection{Data}

[4] We use two high resolution (.5 degree by .5 degree) gridded datasets of observed precipitation over land, from the Climate Research Unit (CRU) version 3.1 [New et al., 1999, 2000; Jones and Harris, 2008] and the Global Precipitation Climatology Centre (GPCC) Full Data Product version 5 [Schneider et al., 2008] and compare with CMIP3 


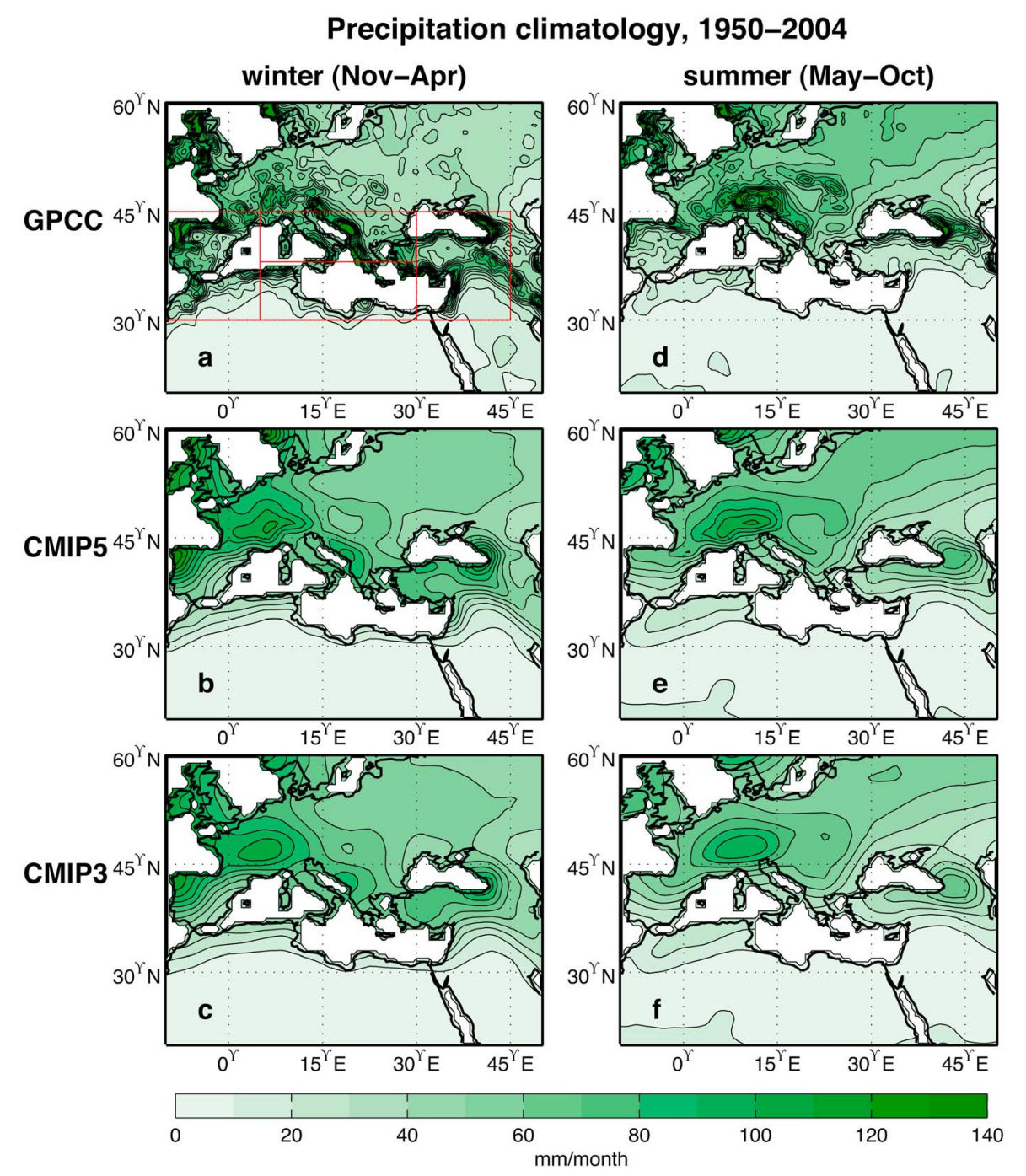

Figure 1. (a-c) Winter half (Nov-Apr) and (d-f) summer half (May-Oct) precipitation climatology, 1950-2004, from the GPCC, CMIP5 multimodel mean and CMIP3 multimodel mean. The red lines in Figure 1a outline the region used in Figure 2.

[Meehl et al., 2007] and CMIP5 [Taylor et al., 2012] global climate models.

[5] We use all available models from the CMIP3 and CMIP5 to create the MMM. In doing so we avoid any subjective bias associated with model selections. We use one run per model in forming the MMM to avoid bias toward any model. In the box plot, however, all model runs are included.

\subsection{Methods}

[6] In order to make spatial intercomparisons possible, all datasets and model outputs were first linearly interpolated to a common $.5^{\circ} \times .5^{\circ}$ horizontal grid for the greaterMediterranean region $(10 \mathrm{~W}-50 \mathrm{E}, 20-60 \mathrm{~N})$. Due to the sparseness of observed station data prior to 1950 we perform all of the analysis with post 1950 data, with the exception of determining the external trend (detailed below). Trends are calculated via a linear least-squares fit to the time series at each grid point. For better comparison with observations, only precipitation over land is considered in this study.
[7] As in Kelley et al. [2012], we employ a model-based S/N maximizing EOF analysis [Allen and Smith, 1997; Venzke et al., 1999; Chang et al., 2000; Ting et al., 2009] to obtain the externally forced precipitation signal. The $\mathrm{S} / \mathrm{N}$ maximizing EOF is first applied to a CMIP5 multi-model ensemble (one run each) for 1900 to 2004 and uses the corresponding models' preindustrial experiments to represent the noise covariance. The technique uses the noise pattern to remove any intermodel differences, structural and temporal, as well as internal variability of the coupled systems that remain in the MMM, providing a maximized "signal". The gridded GPCC observed precipitation is then projected onto the $\mathrm{S} / \mathrm{N}$ first principal component ( $\mathrm{PC} 1$, or signal time series) for the entire period (1900-2004). The externally forced trend from 1950-2004 was then calculated from the reconstructed precipitation at each grid point. More details of the method can be found in the supplementary material.

\section{Precipitation Climatology}

[8] The six month cold and warm season averaged (NovApr and May-Oct, respectively), observed GPCC 
climatologies from 1950 to 2004 are shown in Figures 1a and $1 \mathrm{~d}$. In the vicinity of the Mediterranean Sea, the majority of annual precipitation amounts fall during the six month cold season, whereas over much of the rest of Europe, a substantial contribution comes from the summer half. The corresponding precipitation climatology for CMIP5 and CMIP3 MMMs are shown in the Figures 1b, 1c, 1e, and 1f. The coastal precipitation maximum in the winter half year is captured to some extent by the models, but at a much reduced amplitude. There are some improvements from CMIP3 to CMIP5 however, possibly due in part to the slightly enhanced spatial resolution in the recent generation models. As a result, the spatial pattern correlation (Pearson correlation) between the observed and modeled fields increases slightly from CMIP3 (0.83) to CMIP5 (0.86). For the summer, the agreement is better between models and observations with spatial pattern correlations of 0.95 for CMIP5 and 0.94 for CMIP3. The better agreement between models and observations in summer is mainly due to drier conditions along the Mediterranean coasts compared to winter. As a comparison, the two gridded data sets, CRU and GPCC, are correlated at 0.94 for winter and 0.97 for summer (See Figure $\mathrm{S} 1$ in the auxiliary material). ${ }^{1}$ The Taylor diagram [Taylor, 2001] in Figure S1 compares more closely the individual models' simulations of the precipitation climatologies in winter and summer.

[9] To quantify the model spread and the seasonal cycle of the CMIP5 model simulated climatological rainfall, we show in Figures $2 a-2 d$ the box and whiskers diagram for four selected regions, the entire Mediterranean region, the western, northern, and eastern Mediterranean (areas outlined in Figure 1a), for the four three-month seasons and the annual mean. The box edges indicate the $25 \%$ and $75 \%$ range of the model simulated climatological rainfall while the horizontal bar and red dot inside the box indicate the median and mean model rainfall, respectively, the two horizontal lines outside the box (whiskers) indicate the range of. $35 \%$ and $99.65 \%$, or $+/-2.7$ standard deviations for a normal distribution, and the asterisks show the GPCC observed rainfall. A total of 109 model runs are used from 23 available CMIP5 models (see auxiliary material, Table S1) in Figure 2. In the four regions considered, the observed rainfall shows a clear seasonal cycle with maximum rainfall in the winter and minimum in summer, a characteristic of the Mediterranean climate. It is also clear that the transition seasons often contribute substantially to the annual rainfall total. The CMIP5 models simulate the seasonal cycle reasonably well, but the majority of the models underestimate the winter maximum and overestimate the summer minimum, thus underestimating the amplitude of the seasonal cycle. Compared to CMIP3 (not shown), the CMIP5 model climatologies are wetter in each season and annually, representing improvement relative to the observed with the notable exception of summer, in which case CMIP5 overestimates the summer rainfall more than CMIP3. The CMIP5 models show a larger spread in summer compared to other seasons, despite a higher spatial pattern correlation between MMMs and observations in summer. It is unclear why the intermodel agreement is less during summer. One possibility is that summer precipitation is due less to the large scale circulation but rather is caused

${ }^{1}$ Auxiliary materials are available in the HTML. doi:10.1029/ 2012 GL053416. by convective processes and therefore is more sensitive to each model's physical parameterization scheme. Overall, the climatological rainfall over the Mediterranean region is well simulated by the CMIP5 models. We next examine the rainfall trends simulated in these models.

\section{Precipitation Trends}

[10] The rainfall trends for the period from 1950 to 2004 in the CMIP5 models as compared to observations are summarized in Figures 2e-2h. For the entire Mediterranean region (top right), the mean and median of all models show a modest drying throughout the seasonal cycle with the largest drying trend in spring. But the observed trend shows a large seasonal cycle, ranging from a substantial drying in winter to a wetting trend in autumn. The winter observed rainfall trend for the 55 year period is significant (hereafter indicates a $90 \%$ confidence interval) and larger than $99.65 \%$ of the model trends, with an almost $10 \mathrm{~mm} /$ month reduction, or about $17 \%$ of the total winter season rainfall. For the rest of the seasonal cycle the difference between the observed trend and the model mean trend is smaller, although autumn season precipitation shows a wetting trend (not significant) outside of the middle half of the model predictions. The model underestimation of the observed winter drying comes mainly from the northern and western Mediterranean regions, where the winter observed trends were significant, and less so from the eastern Mediterranean. The largest discrepancies between the observations and models occur in the regions and seasons with strong observed trends. The difference between the models and observations in the autumn trend is dominated by the eastern Mediterranean region, where the observed trend was significant.

[11] Kelley et al. [2012] examined the observed winter precipitation trends for the period 1960 to 2000 and determined the contribution to the total trend from the externally forced (estimated based on CMIP3 simulations) and the natural component (residual). They conclude that the externally forced trend is distinctive in its spatial pattern compared to the pattern of internal climate variability. The discrepancies between modeled and observed winter trends in Figure 2 may indicate that the observed drying was dominated by multidecadal internal variability, such as that seen in the North Atlantic Oscillation (NAO), rather than external radiative forcing. As shown in previous studies [e.g., Kelley et al., 2012; Giorgi and Lionello, 2008], the individual models' multidecadal internal variability may have differing frequency from the 20th Century observations thus producing different internal multidecadal trend. To further examine the externally forced and the total observed trend, we show the total and externally forced (discussed more below) observed trend for 1950-2004 in Figures 3a-3d for winter and summer half years. The winter total observed trend (Figure 3a) shows a significant drying over the western and northern Mediterranean, consistent with Figure 2, coupled with significant wetting trend in northern Europe. This pattern resembles the precipitation anomalies associated with the NAO [Hoerling et al., 2012], thus suggesting the natural variability as a likely cause. The summer observed trend (Figure 3b) is weaker, and has a significant wetting trend around and north of Black Sea. We follow the technique in Kelley et al. [2012] and estimate the externally forced precipitation trend due to radiative forcing using the 


\section{CMIP5 seasonal precipitation \\ Climatology Trend \\ Mediterranean (10W to $45 \mathrm{E}, 30$ to $45 \mathrm{~N}$ )}
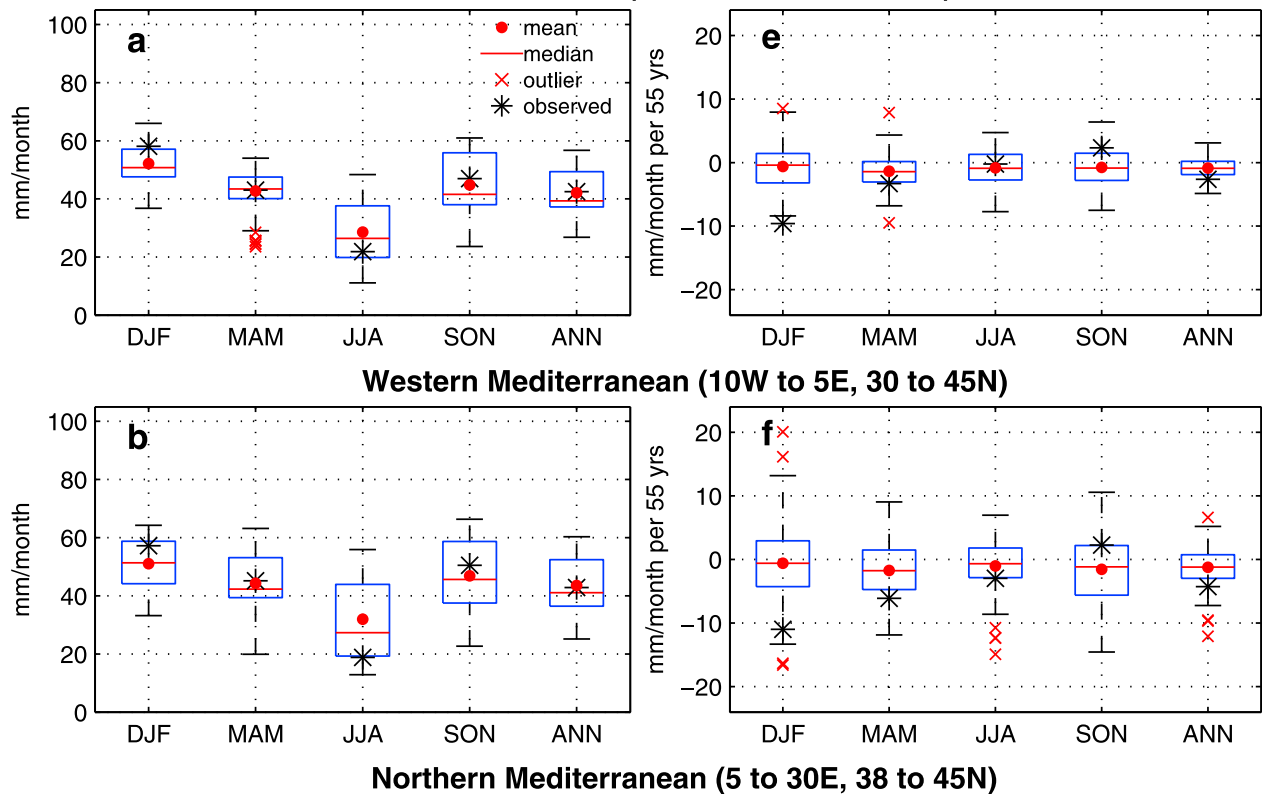

Northern Mediterranean ( 5 to $30 \mathrm{E}, 38$ to $45 \mathrm{~N}$ )
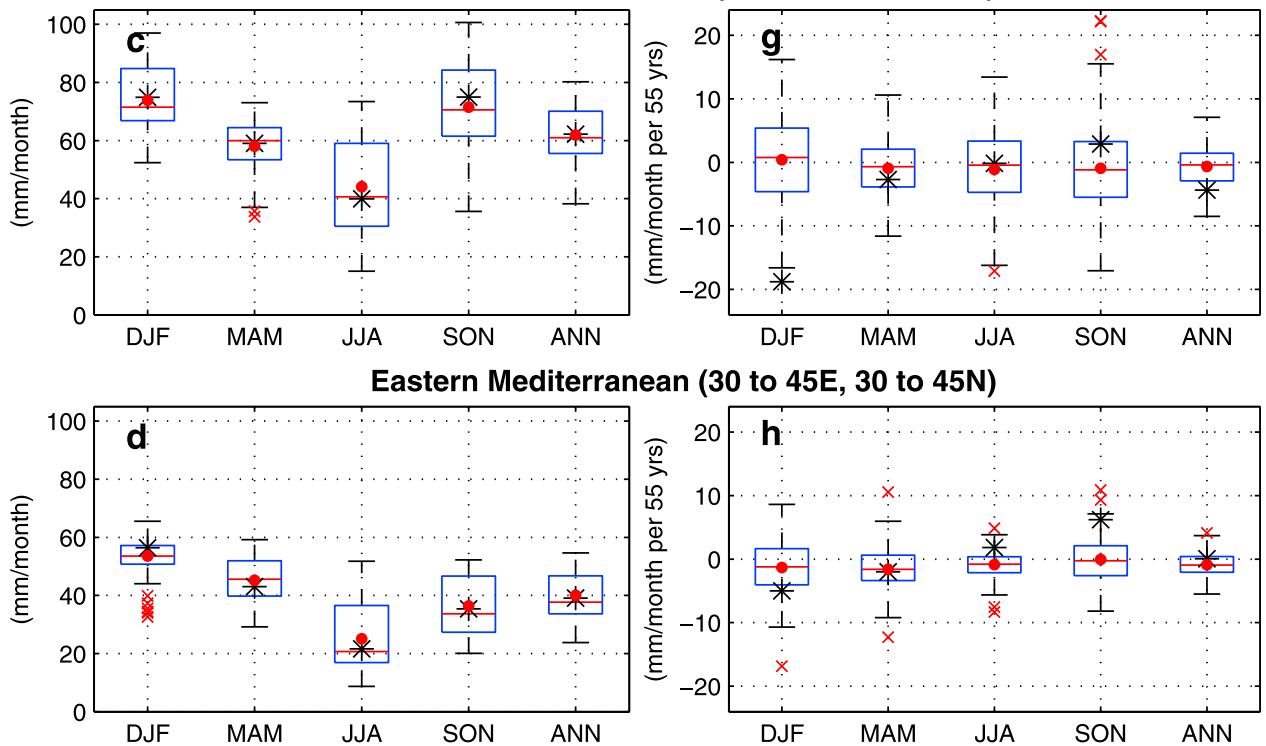

Figure 2. Precipitation (a-d) climatology and (e-h) trends for 1950 to 2004 plotted as box and whisker diagrams using 109 historical runs from 23 CMIP5 models. The 25th and 75th percentiles of the model distributions are shown by the edges of the boxes, and the whiskers as the range of $.35 \%$ and $99.65 \%$ or $+/-2.7$ standard deviations for a normal distribution. Figure legend is as shown in Figure 2a. Results are shown for the entire (Figures 2a and 2e), western (Figures 2b and 2f), northern (Figures $2 \mathrm{c}$ and $2 \mathrm{~g}$ ) and eastern (Figures $2 \mathrm{~d}$ and $2 \mathrm{~h}$ ) Mediterranean region.

signal to noise maximizing EOF PC1 obtained from the CMIP5 multimodel ensemble for the period 1900 to 2004 (see auxiliary material for details). The estimated GPCC externally forced trend for the winter and summer half years, constructed based on the S/N PC1 (Figure S2, bottom left), are shown in Figures $3 \mathrm{c}$ and $3 \mathrm{~d}$. The externally forced trend in Figure $3 \mathrm{c}$ is much reduced compared to the total trend over the western and northern Mediterranean coasts, but slightly larger in the eastern coasts. This result is consistent with Kelley et al. [2012], which focused on a period that is dominated by a positive NAO trend (1960-2000) and thus the total precipitation trend is more dominated by natural variability than indicated in Figures $3 \mathrm{a}$ and $3 \mathrm{c}$. The close resemblance between the observed total and external trends in Figure 3c, however, suggest that the method of estimating the external trend may not be able to remove entirely the trend associated with the NAO-related multidecadal precipitation variability. Over the eastern Mediterranean, the strong externally forced drying there indicates a more likely external cause. The summer observed external trend, while showing a 


\section{Precipitation trend, 1950-2004}
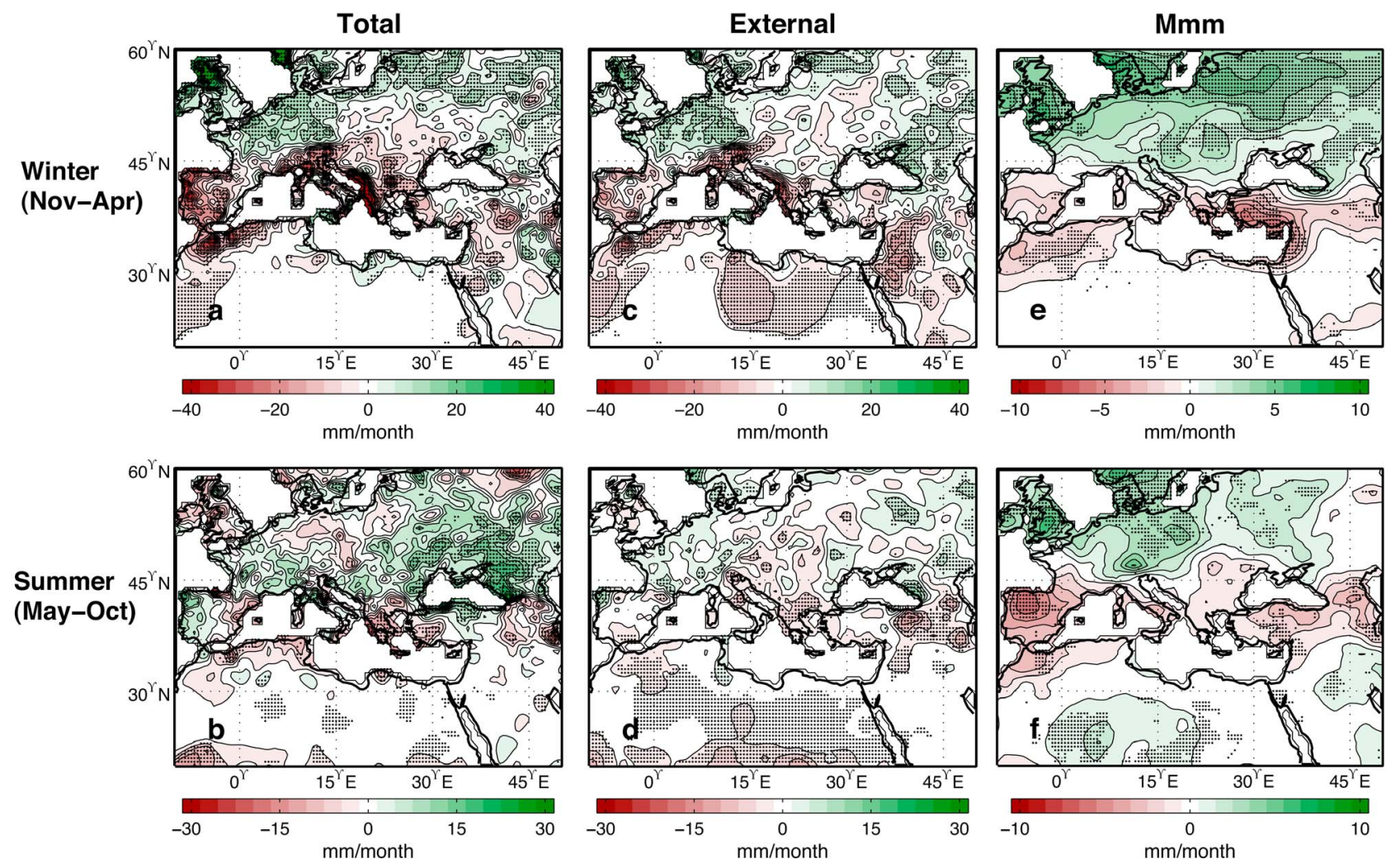

Figure 3. Winter half and summer half GPCC precipitation (a, b) total and (c, d) external trend and (e, f) CMIP5 multimodel mean (one run from each model) trend for the 55 year period from 1950 to 2004 . Significance based on a $90 \%$ confidence interval is shown for the total and external trends. For the MMM, the hatching represents locations where more than $75 \%$ $(17 / 23)$ of models agree on the sign of the trend.

consistent pattern of drying along most of the Mediterranean coasts, exhibits a much weaker amplitude throughout the region than its winter counterpart. The most significant observed drying in summer occurs south and east of the Black Sea, in Turkey.

[12] The CMIP5 MMM trend pattern (Figures 3e and 3f) shows a much weaker drying throughout the Mediterranean region (notice the reduced color scale) compared to the observations, consistent with Figure 2. There is a general agreement between the observed and modeled winter trends in that both have maxima on the western and eastern Mediterranean coasts. However, the maximum over the northern coasts is largely missing from the MMMs. For the summer half year, while the amplitude of the MMM trend is smaller than observed, the difference in amplitude between MMM trend and observed trend is not nearly as large as in winter. There is some correspondence between model and observations in summer drying over Turkey with the exception of eastern Turkey which experienced an observed wetting trend. Over Spain, the MMM has a stronger drying trend in summer compared to observations whereas Portugal shows observed wetting.

[13] It is interesting that the best agreement between CMIP5 MMM trends and the observed trends in both half years is in the eastern Mediterranean region (Figure 3). This is also true in Figure 2, where the eastern Mediterranean observed trend is closer to the model mean than any of the other regions. This indicates that the eastern Mediterranean may have the most significant externally forced drying trend. The greenhouse forcing of the eastern Mediterranean drying is also implicated in Hoerling et al. [2012], where they show that a global uniform warming, and a differential warming, either meridional (tropics versus midlatitudes) or zonal (Indian Ocean versus Pacific), of sea surface temperature (SST) can lead to strong eastern Mediterranean drying. Hoerling et al. [2012] suggest that the regional drying is accomplished primarily through a teleconnection linking global SST warming to increases in subtropical atmospheric high pressure, which in turn reduces cyclogenesis in the eastern Mediterranean basin. Trigo et al. [2010] also explain the recent drought in the Fertile Crescent, the most intense since the 1940s, with dominant high pressure that inhibited synoptic activity over the eastern Mediterranean Sea and favored dry air advection to the region from the northeast. The atmospheric response to the Hoerling et al. [2012] Indian Ocean differential warming experiment has a zonally symmetric expression resembling an expanding Hadley Cell and poleward migration of the storm tracks. Because the eastern Mediterranean is also a region of great water stress, for example in Turkey, Syria and Iraq, and because the future drying due to greenhouse warming will inevitably further deteriorate water availability, it is of vital importance 
to understand the mechanisms which govern the precipitation change there.

\section{Summary}

[14] Using the newest global climate models from the new CMIP5 collection, we show that the Mediterranean precipitation climatology is generally well simulated in both spatial pattern and seasonal cycle. All models simulate the winter maximum and summer minimum in precipitation but the model mean and median slightly underestimate the amplitude of the seasonal cycle. There is a modest improvement of the CMIP5 climatology over CMIP3, possibly because of improved horizontal resolution.

[15] In contrast, the Mediterranean precipitation trends of the last half century in the CMIP5 MMMs and the observations differ significantly, particularly in winter and over the northern Mediterranean region. The CMIP5 MMM trend indicates a modest drying throughout the seasonal cycle, with the strongest drying in the March, April and May spring season. The observed trend, on the other hand, shows a predominantly winter drying. It is not entirely clear what causes this discrepancy, although there is an indication that the strong observed winter drying may be due to multidecadal natural variability [Kelley et al., 2012]. Our estimate of the externally forced trend in observations also shows a predominant winter drying over the region. There is a reasonable agreement in the spatial patterns of the CMIP5 MMM trend and the observed trend over the eastern Mediterranean region, more so in winter than summer.

[16] The modest agreement in spatial patterns between modeled and the observed external trends leads us to further conclude that the radiatively forced portion of the precipitation trend has only begun to emerge relative to natural variability on multidecadal timescales, but that its influence is likely to grow in the future as the forcing increases. Future decreases in Mediterranean region precipitation brought on by global warming, even in the absence of any changes to the internal variability, will have important consequences, reinforcing the need for further research and better understanding of the mechanisms driving the region's hydroclimate. The CMIP5 model ensembles will likely prove a useful tool to this effect.

[17] Acknowledgments. The authors would like to thank the reviewers for their detailed and constructive comments, the Global Decadal Hydroclimate group at Lamont and Columbia for their input, and NOAA and NSF for support. This work is supported under the following grants: NA08OAR5320912, NSF RAPID project AGS-1128172, NOAA NA10OAR4310137, NSF AGS 08-04107 and NOAA NA08OAR4320912.

[18] The Editor thanks the two anonymous reviewers for their assistance in evaluating this paper.

\section{References}

Allen, M. R., and L. A. Smith (1997), Optimal filtering in singular spectrum analysis, Phys. Lett. A, 234(6), 419-428, doi:10.1016/S0375-9601(97) 00559-8.

Chang, P., R. Saravanan, L. Ji, and G. C. Hegerl (2000), The effect of local sea surface temperatures on atmospheric circulation over the tropical Atlantic sector, J. Clim., 13(13), 2195-2216, doi:10.1175/1520-0442 (2000)013<2195:TEOLSS $>2.0$. CO; 2 .

Feldstein, S. B. (2002), The recent trend and variance increase of the annular mode, J. Clim., 15(1), 88-94, doi:10.1175/1520-0442(2002)015<0088: TRTAVI $>2.0 . \mathrm{CO} ; 2$.

Gillett, N., H. Graf, and T. Osborn (2003), Climate change and the North Atlantic Oscillation, in The North Atlantic Oscillation: Climatic
Significance and Environmental Impact, Geophys. Monogr. Ser., vol. 134, edited by J. W. Hurrell et al., pp. 193-210, AGU, Washington, D. C.

Giorgi, F., and P. Lionello (2008), Climate change projections for the Mediterranean region, Global Planet. Change, 63, 90-104, doi:10.1016/ j.gloplacha.2007.09.005.

Held, I. M., and B. J. Soden (2006), Robust responses of the hydrological cycle to global warming, J. Clim., 19(21), 5686-5699, doi:10.1175/ JCLI3990.1.

Hoerling, M. P., J. Eischeid, J. Perlwitz, X. Quan, T. Zhang, and P. Pegion (2012), On the increased frequency of Mediterranean drought, J. Clim., 25, 2146-2161, doi:10.1175/JCLI-D-11-00296.1.

Hurrell, J. W., Y. Kushnir, G. Ottersen, and M. Visbeck (2003), An overview of the North Atlantic Oscillation, in The North Atlantic Oscillation: Climatic Significance and Environmental Impact, Geophys. Monogr. Ser., vol. 134, edited by J. W. Hurrell et al., pp. 1-35, AGU, Washington, D. C., doi:10.1029/134GM01.

Intergovernmental Panel on Climate Change (IPCC) (2007), Climate Change 2007: The Physical Science Basis. Contribution of Working Group I to the Fourth Assessment Report of the Intergovernmental Panel on Climate Change, edited by S. Solomon et al., 996 pp., Cambridge Univ. Press, Cambridge, U. K.

Jacobeit, J., A. Dunkeloh, and E. Hertig (2007), Mediterranean rainfall changes and their causes, in Global Change: Enough Water for All?, edited by J. Lozan et al., pp. 195-199, Wiss. Auswertungen, Hamburg, Germany.

Jones, P., and I. Harris (2008), CRU Time Series (TS) High Resolution Gridded Datasets, http://badc.nerc.ac.uk/view/badc.nerc.ac.uk_ATOM dataent 1256223773328276, Clim. Res. Unit, Univ. of East Anglia, Norwich, U. K

Kelley, C., M. Ting, R. Seager, and Y. Kushnir (2012), The relative contributions of radiative forcing and internal climate variability to the late 20th century winter drying of the Mediterranean region, Clim. Dyn., 38(9-10), 2001-2015, doi:10.1007/s00382-011-1221-z.

Lu, J., G. A. Vecchi, and T. A. Reichler (2007), Expansion of the Hadley cell under global warming, Geophys. Res. Lett., 34, L06805, doi:10.1029/ 2006 GL028443.

Mariotti, A., and A. Dell'Aquila (2012), Decadal climate variability in the Mediterranean region: Roles of large-scale forcings and regional processes, Clim. Dyn., 38(5-6), 1129-1145, doi:10.1007/s00382-0111056-7.

Meehl, G. A., C. Covey, T. Delworth, M. Latif, B. McAvaney, J. F. B. Mitchell, R. J. Stouffer, and K. E. Taylor (2007), The WCRP CMIP3 multimodel dataset: A new era in climate change research, Bull. Am. Meteorol. Soc., 88(9), 1383-1394, doi:10.1175/BAMS-88-9-1383.

New, M., M. Hulme, and P. D. Jones (1999), Representing twentieth century space-time climate variability. Part 1: Development of a 1961-90 mean monthly terrestrial climatology, J. Clim., 12, 829-856, doi:10.1175/ 1520-0442(1999)012<0829:RTCSTC $>2.0 . C O ; 2$.

New, M., M. Hulme, and P. D. Jones (2000), Representing twentieth century space-time climate variability. Part 2: development of 1901-96 monthly grids of terrestrial surface climate, J. Clim., 13, 2217-2238, doi:10.1175/1520-0442(2000)013<2217:RTCSTC>2.0.CO;2.

Osborn, T. J. (2004), Simulating the winter North Atlantic Oscillation: The roles of internal variability and greenhouse gas forcing, Clim. Dyn., 22(6-7), 605-623, doi:10.1007/s00382-004-0405-1.

Schneider, E. K., L. Bengtsson, and Z. Z. Hu (2003), Forcing of Northern Hemisphere climate trends, J. Atmos. Sci., 60(12), 1504-1521, doi:10.1175/ 1520-0469(2003)060<1504:FONHCT $>2.0$. CO;2.

Schneider, U., T. Fuchs, A. Meyer-Christoffer, and B. Rudolf (2008), Global precipitation analysis products of the GPCC, Global Precip. Climatol. Cen., Deutsch. Wetterdienst, Offenbach, Germany.

Seager, R., et al. (2007), Model projections of an imminent transition to a more arid climate in southwestern North America, Am. Sci., 316(5828), $1181-1184$

Seager, R., N. Naik, and G. A. Vecchi (2010), Thermodynamic and dynamic mechanisms for large-scale changes in the hydrological cycle in response to global warming, J. Clim., 23(17), 4651-4668, doi:10.1175/ 2010JCLI3655.1

Taylor, K. E. (2001), Summarizing multiple aspects of model performance in a single diagram, J. Geophys. Res., 106(D7), 7183-7192, doi:10.1029/ 2000JD900719.

Taylor, K. E., R. J. Stouffer, and G. A. Meehl (2012), An overview of CMIP5 and the experiment design, Bull. Am. Meteorol. Soc., 93(4), 485-498, doi:10.1175/BAMS-D-11-00094.1.

Thompson, D. W. J., S. Lee, and M. P. Baldwin (2003), Atmospheric processes governing the Northern Hemisphere annular mode/North Atlantic Oscillation, in The North Atlantic Oscillation: Climatic Significance and Environmental Impact, Geophys. Monogr. Ser., vol. 134, edited by J. W. Hurrell et al., pp. 81-112, AGU, Washington, D. C., doi:10.1029/ 134GM05. 
Ting, M. F., Y. Kushnir, R. Seager, and C. H. Li (2009), Forced and internal twentieth-century SST trends in the North Atlantic, J. Clim., 22(6), 1469-1481, doi:10.1175/2008JCLI2561.1.

Trigo, R. M., C. Gouveia, and D. Barriopedro (2010), The intense 2007-2009 drought in the Fertile Crescent: Impact and associated atmospheric circulation, Agric. Meteorol., 150, 1245-1257, doi:10.1016/j. agrformet.2010.05.006.

Venzke, S., M. R. Allen, R. T. Sutton, and D. P. Rowell (1999), The atmospheric response over the North Atlantic to decadal changes in sea surface temperature, J. Clim., 12(8), 2562-2584, doi:10.1175/15200442(1999)012<2562:TAROTN>2.0.CO;2.

Wu, Y., M. F. Ting, R. Seager, H. Huang, and M. Cane (2011), Changes in storm tracks and energy transports in a warmer climate simulated by the GFDL CM2.1 model, Clim. Dyn., 37(1-2), 53-72, doi:10.1007/s00382010-0776-4.

Yin, J. H. (2005), A consistent poleward shift of the storm tracks in simulations of $21 \mathrm{st}$ century climate, Geophys. Res. Lett., 32, L18701, doi:10.1029/2005GL023684 